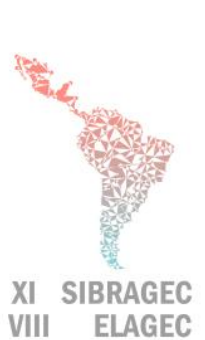

VIII ELAGEC

\section{SIMPÓSIO BRASILEIRO DE GESTÃO E ECONOMIA DA CONSTRUÇÃO}

VIII ENCUENTRO LATINOAMERICANO DE GESTIÓN Y ECONOMÍA DE LA CONSTRUCCIÓN

Do conhecimento à ação: práticas avançadas de gestão da produção Londrina, Paraná, Brasil. 23 a 25 de Outubro de 2019

\title{
MATURIDADE DA CULTURA DE SEGURANÇA NO TRABALHO: APLICAÇÃO DO MODELO DE HUDSON
}

\author{
GRANDINETE, Isabella C. (1); SOUSA, Tatiane G. de (2); BRANDSTETTER, \\ Maria Carolina G. O. (3)
}

(1) Escola de Engenharia Civil e Ambiental, Universidade Federal de Goiás, e-mail: isacampanholo@gmail.com (2) Escola de Engenharia Civil e Ambiental, Universidade Federal de Goiás, e-mail: gtati.sousa@gmail.com, (3) Escola de Engenharia Civil e Ambiental, Universidade Federal de Goiás, e-mail: mariacarolina.brands@gmail.com

\begin{abstract}
This study aims to contribute to an improvement in the management of workers health and safety. Through a bibliographical review the work brings several concepts about safety culture at work, showing that there is still a consensus among the scholars about the subject and showing the importance of understanding the same for organizations success. It sought to analyze the maturity degree of work safety culture in a construction company in Goiânia, through application of a questionnaire based on Hudson's model. The model is an important managerial tool, because it can define in which of the five stages (pathological, reactive, bureaucratic, proactive and sustainable) the company finds itself, through the way it treats the following factors: information, organizational learning, involvement, communication and commitment. The result of this research demonstrated that both the workers and the administrative team attribute to the organization a transition between the proactive and sustainable stage, but most of it is allocated in the sustainable stage, considered the ideal stage. Safety culture is of paramount importance for improving the well-being of workers towards the work environment, as it contributes to reduction of risks and accidents, requiring a greater investment in this area, either through new studies and research or by the entrepreneurs' awareness.
\end{abstract}

Keywords: Safety, Safety culture, Maturity degree, Civil Construction.

\section{INTRODUÇÃ̃O}

No Brasil foram registrados acima de 1,7 milhão de acidentes de trabalho no triênio 2015-2017. A construção civil está entre as seis atividades econômicas responsáveis por aproximadamente $25 \%$ do total de acidentes ocorridos (AEAT, 2017).

A preocupação com a segurança e saúde do trabalhador está cada dia maior, seja pelo aumento dos números de acidentes ocorridos no trabalho, seja pelo custo final que os acidentes acarretam ao empregador ou pela pressão popular para uma maior conscientização sobre a importância de uma boa prática de segurança no trabalho.

A fim de se compreender os fatores que estão ligados a um número tão alto de acidentes de trabalho, a abordagem sobre este assunto está cada vez mais integrada a questões de segurança, saúde e meio ambiente do trabalho, além de uma cultura de segurança bem compartilhada (GONÇALVES FILHO; ANDRADE; MARINHO, 2011). 


\section{SIBRAGEC - ELAGEC 2019 - de 23 a 25 de Outubro - LONDRINA - PR}

Pontes e Honório (2008) afirmam que ainda que os meios existentes atualmente, como as leis e os equipamentos de segurança individuais e coletivos, sejam suficientes para evitar a maioria das situações de riscos que os trabalhadores se expõem todos os dias, isto não repercute nos índices de acidentes de trabalho. Os autores acreditam que uma boa cultura de segurança, praticada constantemente pela empresa, possa contribuir para a reversão desse quadro.

Embora seja um tema de grande relevância, no Brasil ainda não existem estudos empíricos, e nem modelos para avaliar o grau de maturidade da cultura de segurança no trabalho (GONÇALVES FILHO; ANDRADE; MARINHO, 2011). O conceito do grau de maturidade que há na cultura de segurança do trabalho foi citado pela primeira vez, em 1988, no relatório do acidente nuclear em Chernobyl; desde então diversos autores estudam sobre o seu conceito, porém no Brasil é considerado um tema relativamente novo, em termos de discussões e estudos originados, o que indica a importância de cultivar e empreender o seu potencial para melhorar a segurança do trabalho.

Existe um consenso entre os pesquisadores de que a cultura da segurança interfere diretamente na segurança dos trabalhadores. Para este trabalho, o conceito de cultura de segurança adotado foi baseado em Reason (1997), Hopkins (2005) e Cooper (2000), como sendo um conjunto de subculturas, envolvendo os indivíduos, a organização, os valores e as crenças que influenciam nas práticas coletivas em relação à saúde e segurança do trabalho.

Hudson (2001) criou um modelo que possibilita classificar o grau de maturidade da cultura de segurança do trabalho em uma empresa. Por meio do método desenvolvido por Gonçalves Filho (2011) é possível classificar em qual estágio a empresa se encontra.

A cultura de segurança necessita ser avaliada como um valor pela organização lidando com ambiente e indivíduos engajados para o seu desenvolvimento. Para obter um ambiente equilibrado é preciso abordar temas como a segurança, saúde e o meio ambiente de forma integrada (GONÇALVES FILHO; ANDRADE; MARINHO, 2011).

Diante deste contexto, este trabalho tem por objetivo identificar o grau de maturidade da cultura de segurança do trabalho em uma obra residencial de uma construtora na cidade de Goiânia, com base no modelo de Hudson (2001), aplicado em dois níveis organizacionais: operários e equipe administrativa.

\section{SÍNTESE BIBLIOGRÁFICA}

Hudson (2001) dividiu a cultura em dois aspectos: estática, que se refere aos valores da organização e opiniões dos membros, e dinâmica, referindo ao que é feito pela organização para que esta cultura seja realizada. O Quadro 1 mostra as definições dos quatro componentes que melhor auxiliam a identificação da cultura na organização.

É importante conhecer o tipo de cultura da empresa e qual será o impacto na segurança, para que seja possível realizar medidas preventivas. Para isso é necessário saber em qual estágio de maturidade a cultura de segurança da empresa se encontra. Westrum (1993) criou inicialmente três estágios da cultura organizacional: patológica, calculativa e construtiva. Utilizando-se deles, Hudson (2001) criou um modelo capaz de classificar o grau de maturidade da cultura de segurança da organização e adicionou mais dois estágios, o reativo e o proativo. O modelo contém cinco estágios, evoluindo do inicial, chamado de patológico até o estágio final ideal, o construtivo, conforme a Figura 1. 
SIBRAGEC - ELAGEC 2019 - de 23 a 25 de Outubro - LONDRINA - PR

Quadro 1 - Definições da cultura em uma corporação

\begin{tabular}{|l|l|}
\hline Componentes & Definição \\
\hline Valores da Corporação & O que a organização considera como importante. \\
\hline Opinião da Corporação & $\begin{array}{l}\text { O que a organização acredita sobre o mundo, como } \\
\text { ele irá reagir. Opiniões sobre o que pode funcionar na } \\
\text { organização ou não. }\end{array}$ \\
\hline $\begin{array}{l}\text { Métodos comuns para solucionar } \\
\text { problemas }\end{array}$ & $\begin{array}{l}\text { Como os diversos tipos de problemas são } \\
\text { solucionados pela empresa. }\end{array}$ \\
\hline Práticas trabalhistas comuns & $\begin{array}{l}\text { Como as pessoas se relacionam com o trabalho, } \\
\text { pequenas reuniões, projetos administrativos etc. }\end{array}$ \\
\hline
\end{tabular}

Fonte: Traduzido de HUDSON (2001)

\section{Figura 1 - Modelo de maturidade da cultura de segurança}

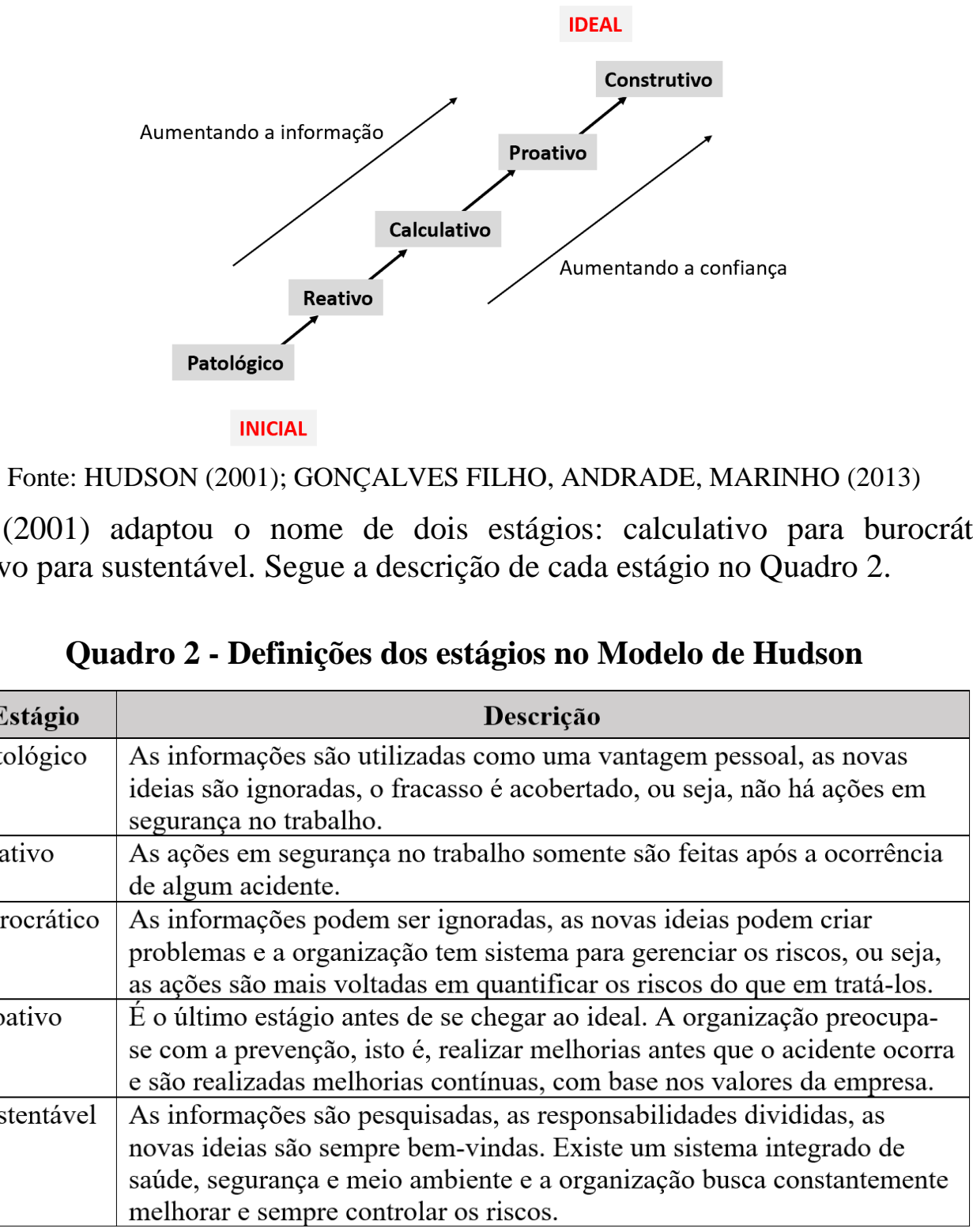

Fonte: HUDSON (2001)

Para mensurar os estágios da cultura de segurança são utilizados fatores ou indicativos da sua maturidade, porém não existe uma padronização. Gonçalves Filho, Andrade e Marinho (2011; 2013) juntaram cinco fatores mais presentes na literatura (Quadro 3). 
SIBRAGEC - ELAGEC 2019 - de 23 a 25 de Outubro - LONDRINA - PR

Quadro 3 - Definições dos fatores no Modelo de Hudson

\begin{tabular}{|l|l|}
\hline \multicolumn{1}{|c|}{ Fator } & \multicolumn{1}{c|}{ Descrição } \\
\hline Informação & $\begin{array}{l}\text { É a confiança dos trabalhadores em relatar os incidentes, erros } \\
\text { ou acidentes ocorridos, além de gerar indicadores a fim de } \\
\text { monitorar o desemprenho da segurança no trabalho. }\end{array}$ \\
\hline $\begin{array}{l}\text { Aprendizagem } \\
\text { Organizacional }\end{array}$ & $\begin{array}{l}\text { É como a organização trata as informações recebidas, se é feita a } \\
\text { análise dos incidentes ou acidentes e se há uma busca por } \\
\text { melhoria contínua na segurança. }\end{array}$ \\
\hline Envolvimento & $\begin{array}{l}\text { É a participação dos operários nas questões que são relacionadas } \\
\text { à segurança do trabalho. }\end{array}$ \\
\hline Comunicação & $\begin{array}{l}\text { É a forma, a oportunidade de como é feita a comunicação sobre } \\
\text { temas relativos à segurança, se ela é compreendida, se há um } \\
\text { canal aberto entre operários e superiores e se é efetiva. }\end{array}$ \\
\hline Comprometimento & $\begin{array}{l}\text { Ele é evidenciado pela proporção de recursos (tempo, dinheiro, } \\
\text { pessoas) alocados para a gestão de segurança, se existe algum } \\
\text { sistema de segurança, saúde e meio ambiente. Está mais voltado } \\
\text { para a prática do que apenas para as políticas escritas. }\end{array}$ \\
\hline
\end{tabular}

Fonte: GONÇALVES FILHO, ANDRADE, MARINHO (2013)

\section{MÉTODO DE PESQUISA}

A proposta deste trabalho foi identificar o estágio de maturidade da cultura de segurança de trabalho na construção civil, por meio de um estudo de caso na cidade de Goiânia. A coleta dos dados se baseou em observações in loco, entrevistas não estruturadas com o corpo gerencial e na aplicação de um questionário baseado no modelo de Hudson (2001).

Como critérios para a escolha da empresa podem ser citadas a disponibilidade para participação na pesquisa e a existência de um sistema de gestão de segurança do trabalho. A construtora escolhida tem em seu portfólio obras de diferentes segmentos, além de possuir um Sistema de Gestão Integrada englobando as certificações ISO 9001, ISO 14001 e OHSAS 18001.

A definição de qual estágio a empresa se encontra foi feita identificando como ela trata cada um dos cincos fatores, apresentados no Quadro 3, por meio de um questionário fechado composto por 21 perguntas de múltipla escolha. A Figura 2 ilustra a representação das questões em seus respectivos fatores.

\section{Figura 2 - Representação das questões em seus respectivos fatores}

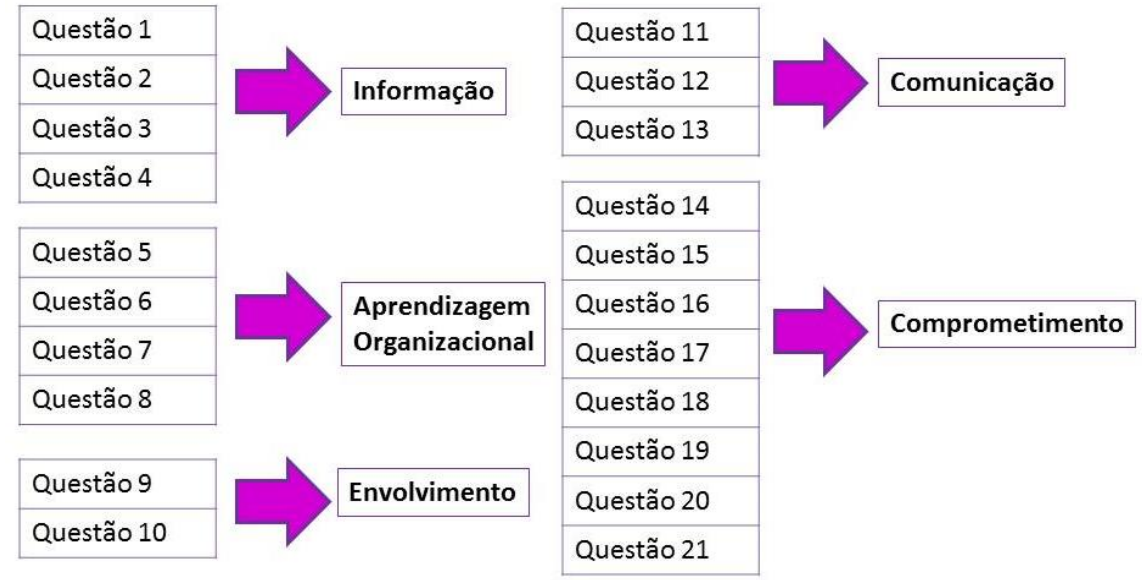

Fonte: Autores 
A Figura 3 ilustra parte do modelo dos itens do questionário desenvolvido. Na ilustração são apresentados os itens do fator Comprometimento, que foram base para as questões 14 a 21 do questionário.

\section{Figura 3 - Itens relativos ao fator Comprometimento no Modelo de Maturidade da Cultura de Segurança}

\begin{tabular}{|c|c|c|c|c|}
\hline \multicolumn{5}{|c|}{ Comprometimento } \\
\hline Patologico & Reativo & Burocrático & Proativo & Sustentável \\
\hline $\begin{array}{l}\text { 1. Não existe na empresa } \\
\text { planejamento em segurança no } \\
\text { trabalho. } \\
\text { 2. A empresa não faz auditorias } \\
\text { em segurança no trabalho. }\end{array}$ & $\begin{array}{l}\text { 1. } 0 \text { planejamento da empresa } \\
\text { para a segurança no trabalho é } \\
\text { voltado apenas para corrigir o } \\
\text { que deu errado no passado. } \\
\text { 2. A empresa faz auditorias em } \\
\text { segurança no trabalho apenas }\end{array}$ & $\begin{array}{l}\text { 1. } 0 \text { planejamento da empresa } \\
\text { para a segurança no trabalho } \\
\text { é voltado apenas para a } \\
\text { identificação e análise dos } \\
\text { riscos existentes no ambiente } \\
\text { de trabalho. }\end{array}$ & $\begin{array}{l}\text { 1. } 0 \text { planejamento da } \\
\text { empresa para a segurança } \\
\text { no trabalho não é integrado } \\
\text { com o planejamento das } \\
\text { outras áreas da empresa } \\
\text { (como, por exemplo, a área } \\
\text { de produção). }\end{array}$ & $\begin{array}{l}\text { 1. } 0 \text { planejamento da empresa } \\
\text { para a segurança no trabalho é } \\
\text { integrado com o planejamento } \\
\text { das outras áreas da empresa } \\
\text { (como, por exemplo, a área de } \\
\text { produção). }\end{array}$ \\
\hline $\begin{array}{l}\text { 3. A empresa não faz } \\
\text { investimentos em segurança no } \\
\text { trabalho. }\end{array}$ & $\begin{array}{l}\text { depois que acidentes graves } \\
\text { ocorrem. } \\
\text { 3. A empresa faz investimentos }\end{array}$ & $\begin{array}{l}\text { 2. A empresa faz auditorias } \\
\text { em segurança no trabalho } \\
\text { apenas nas áreas onde existem } \\
\text { riscos de acidentes. }\end{array}$ & $\begin{array}{l}\text { 2. A empresa faz auditorias } \\
\text { em segurança do trabalho } \\
\text { em todos seus setores. }\end{array}$ & $\begin{array}{l}\text { 2. A empresa faz auditorias } \\
\text { em segurança do trabalho em } \\
\text { todos seus setores. }\end{array}$ \\
\hline $\begin{array}{l}\text { 4. A empresa não realiza } \\
\text { treinamento em segurança no } \\
\text { trabalho. }\end{array}$ & $\begin{array}{l}\text { em segurança no trabalho } \\
\text { apenas depois que acidentes } \\
\text { graves ocorrem. }\end{array}$ & $\begin{array}{l}\text { 3. A empresa faz investimento } \\
\text { em segurança no trabalho } \\
\text { apenas nas áreas onde existem }\end{array}$ & $\begin{array}{l}\text { 3. A empresa investe } \\
\text { continuamente em segurança } \\
\text { no trabalho em todos os seus }\end{array}$ & $\begin{array}{l}\text { 3. A empresa investe } \\
\text { continuamente em segurança } \\
\text { no trabalho em todos os seus } \\
\text { setores. }\end{array}$ \\
\hline 5. A empresa não possui equipe & 4. A empresa realiza & riscos de acidentes. & setores. & \\
\hline $\begin{array}{l}\text { para apoio à segurança no } \\
\text { trabalho. } \\
\text { 6. A segurança no trabalho não }\end{array}$ & $\begin{array}{l}\text { treinamento em segurança } \\
\text { no trabalho apenas apos a } \\
\text { ocorrência de acidentes graves. }\end{array}$ & $\begin{array}{l}\text { 4. A empresa realiza } \\
\text { treinamentos em segurança } \\
\text { no trabalho apenas para os }\end{array}$ & $\begin{array}{l}\text { 4. A empresa realiza } \\
\text { continuamente treinamento } \\
\text { em segurança no trabalho }\end{array}$ & $\begin{array}{l}\text { 4. A empresa realiza } \\
\text { continuamente treinamento } \\
\text { em segurança no trabalho para } \\
\text { todos os empregados. }\end{array}$ \\
\hline $\begin{array}{l}\text { é prioridade na empresa. } \\
\text { 7. Não existem procedimentos } \\
\text { em segurança no trabalho na } \\
\text { empresa. }\end{array}$ & $\begin{array}{l}\text { 5. A empresa possui uma } \\
\text { equipe pequena para apoio à } \\
\text { segurança no trabalho. }\end{array}$ & $\begin{array}{l}\text { empregados que trabalham } \\
\text { em ambientes onde existem } \\
\text { riscos de acidentes. }\end{array}$ & $\begin{array}{l}\text { para todos os empregados. } \\
\text { 5. A empresa possui uma } \\
\text { equipe com dimensão } \\
\text { adequada para apoio à } \\
\text { segurança no trabalho. }\end{array}$ & $\begin{array}{l}\text { 5. A empresa não possui } \\
\text { uma equipe para apoio à } \\
\text { segurança no trabalho porque } \\
\text { a responsabilidade pela área é } \\
\text { distribuida por toda a empresa. }\end{array}$ \\
\hline $\begin{array}{l}\text { 8. A empresa contrata } \\
\text { terceirizadas sem preocupação } \\
\text { com a segurança no trabalho. }\end{array}$ & $\begin{array}{l}\text { 6. A segurança no trabalho } \\
\text { torna-se prionitária na empresa } \\
\text { somente quando ocorrem } \\
\text { acidentes graves. } \\
\text { 7. 0s procedimentos em }\end{array}$ & $\begin{array}{l}\text { 5. A empresa possui uma } \\
\text { equipe com dimensão } \\
\text { adequada para apoio à } \\
\text { segurança no trabalho. } \\
\text { 6. A segurança no trabalho }\end{array}$ & $\begin{array}{l}\text { 6. A segurança no trabalho } \\
\text { não é a maior prioridade na } \\
\text { empresa. }\end{array}$ & $\begin{array}{l}\text { 6. A segurança no trabalho é a } \\
\text { maior prioridade na empresa. }\end{array}$ \\
\hline & $\begin{array}{l}\text { segurança no trabalho são } \\
\text { escritos pela empresa apenas } \\
\text { depois que acidentes graves } \\
\text { ocorrem. }\end{array}$ & $\begin{array}{l}\text { não é a maior prioridade na } \\
\text { empresa. } \\
\text { 7. Os procedimentos em } \\
\text { segurança no trabalho }\end{array}$ & $\begin{array}{l}\text { 7. Os procedimentos em } \\
\text { segurança no trabalho } \\
\text { da empresa apresentam } \\
\text { as melhores práticas para }\end{array}$ & $\begin{array}{l}\text { 7. Os procedimentos em } \\
\text { segurança no trabalho da } \\
\text { empresa apresentam as } \\
\text { melhores práticas para executar } \\
\text { a tarefa, e são constantemente }\end{array}$ \\
\hline & $\begin{array}{l}\text { 8. A empresa dá atenção à } \\
\text { segurança no trabalho das } \\
\text { terceirizadas apenas depois que }\end{array}$ & $\begin{array}{l}\text { existentes na empresa são } \\
\text { voltados apenas para os } \\
\text { setores onde existem riscos de }\end{array}$ & $\begin{array}{l}\text { executar a tarefa, mas } \\
\text { não são constantemente } \\
\text { revisados para adequá-los à }\end{array}$ & $\begin{array}{l}\text { revisados para adequá-los a } \\
\text { realidade do trabalho. }\end{array}$ \\
\hline & acidentes graves acontecem. & acidentes. & realidade do trabalho. & $\begin{array}{l}\text { 8. A empresa considera as } \\
\text { terceirizadas parte integrante }\end{array}$ \\
\hline & & $\begin{array}{l}\text { 8. A empresa antes de } \\
\text { contratar terceirizadas realiza } \\
\text { pré-qualificação em segurança } \\
\text { do trabalho, mas não faz } \\
\text { acompanhamento posterior }\end{array}$ & $\begin{array}{l}\text { 8. A empresa antes de } \\
\text { contratar terceirizadas } \\
\text { realiza pré-qualificação em } \\
\text { segurança do trabalho, mas } \\
\text { não faz acompanhamento } \\
\text { posterior. }\end{array}$ & $\begin{array}{l}\text { de seu sistema de gestão de } \\
\text { segurança no trabalho. }\end{array}$ \\
\hline
\end{tabular}

Fonte: Adaptado de HUDSON (1998) e GONÇALVES FILHO (2011)

Foi decidido previamente que a pesquisa seria aplicada em dois níveis da organização: em uma amostra de operários escolhidos aleatoriamente (não devendo exercer cargo de supervisão e não serem terceirizados) e na equipe administrativa da empresa. O modelo não estabelece um contingente mínimo de entrevistados. Buscou-se comparar os resultados dos dois níveis organizacionais e avaliar em qual grau de maturidade cada nível achava que a empresa se encontrava. O questionário foi respondido por $60 \%$ dos 85 operários e $90 \%$ das 10 pessoas da equipe administrativa, totalizando 60 respondentes. Também foram realizadas visitas técnicas à obra em questão, com o intuito de conhecer melhor a construtora, suas ações, práticas do dia a dia e observar os trabalhadores no quesito segurança. 
SIBRAGEC - ELAGEC 2019 - de 23 a 25 de Outubro - LONDRINA - PR

\section{RESULTADOS E DISCUSSÕES}

As análises gráficas quanto à visão dos operários e da equipe administrativa podem ser visualizadas nas Figuras 4 e 5.

Figura 4 - Estágio da cultura de segurança no trabalho na visão dos operários

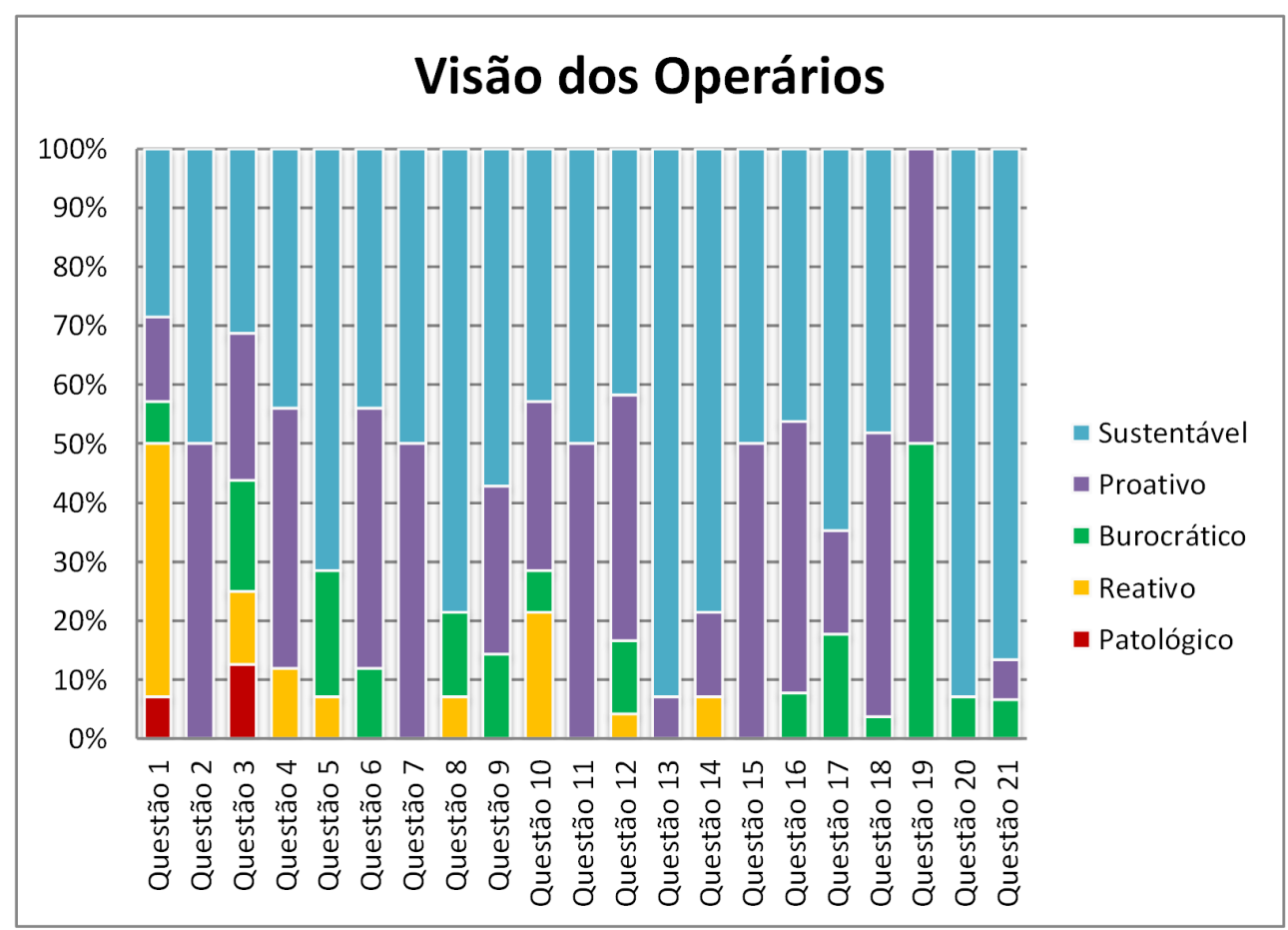

Fonte: Autores

Figura 5 - Estágio da cultura de segurança no trabalho na visão da equipe administrativa

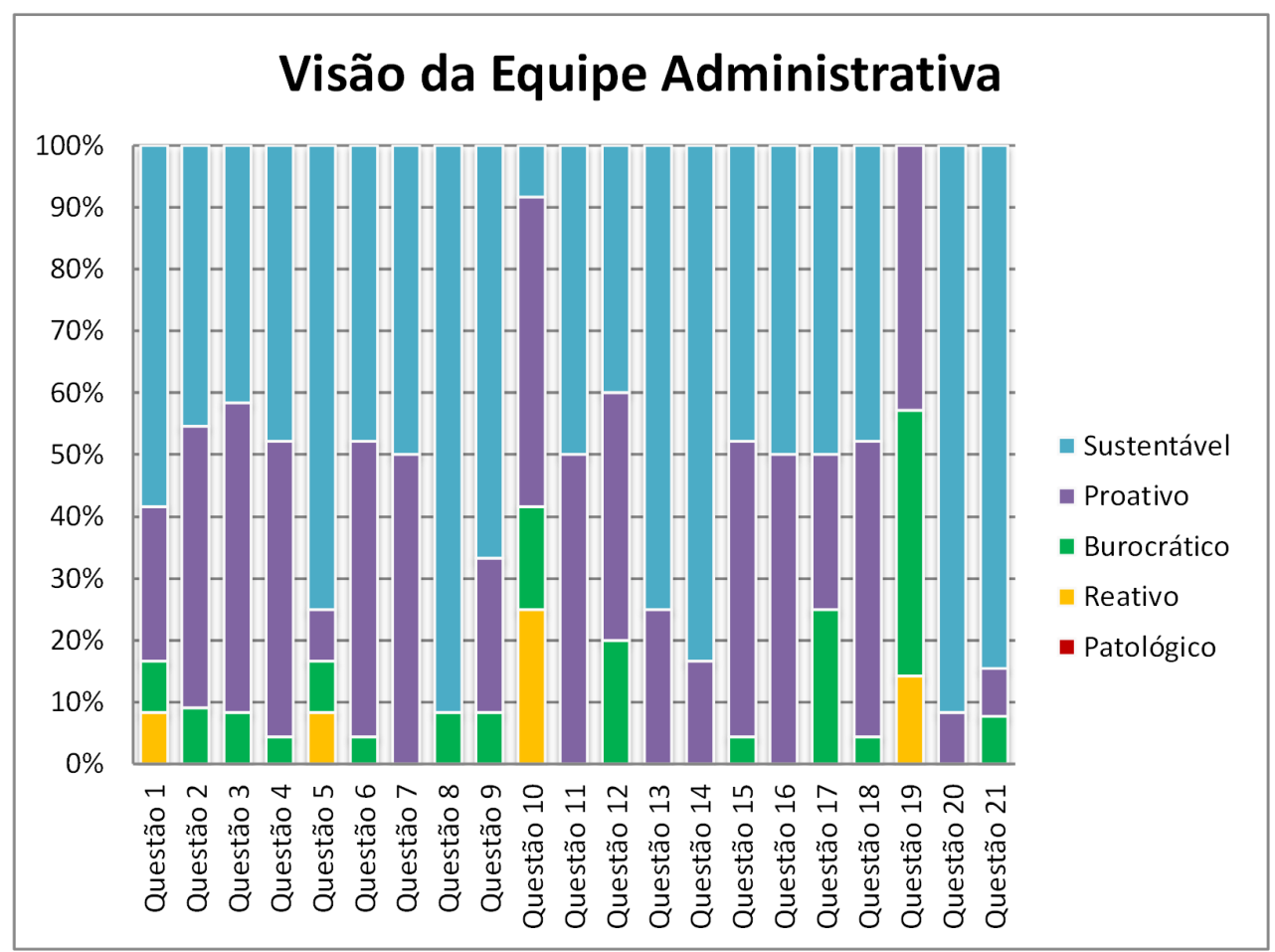

Fonte: Autores 


\section{SIBRAGEC - ELAGEC 2019 - de 23 a 25 de Outubro - LONDRINA - PR}

Os resultados apontam duas possibilidades de estágio, Proativo e Sustentável. De acordo com Gonçalves Filho (2011), isto acontece pois não há uma fronteira definida, na qual termina um estágio e inicia-se o outro.

A comparação dos dois níveis organizacionais pode indicar algumas diferenças mais acentuadas:

- A primeira diferença é perceptível nas primeiras questões (Fator Informação) no nível operacional o estágio patológico apareceu em duas questões com praticamente $10 \%$ das respostas. Na equipe administrativa este estágio não apareceu em nenhum momento. A informação pode ser um fator que seja necessário maior preocupação por parte dos gerentes, pois os empregados não se sentem à vontade para relatar as ocorrências atípicas. Percebe-se no nível operacional uma alocação no estágio reativo maior do que no nível da administração, onde há predominância dos estágios proativo e sustentável.

- Dentro do fator envolvimento há uma diferença relevante na questão 10, cuja pergunta é sobre o interesse dos empregados em participar de palestras relacionadas à segurança. Os administradores acham que a maioria dos trabalhadores tem interesse em participar livremente ou somente quando ocorrem acidentes graves, alocando este fator no estágio proativo e reativo, respectivamente. Porém, os próprios operários demonstram, com mais de 40\%, que todos têm interesse em participar de temas relacionados à segurança, resultando o estágio sustentável.

- Nas questões sobre comprometimento, pergunta-se se a segurança do trabalho é prioridade para a empresa (questão 17). No nível gerencial os estágios burocrático e proativo representam $50 \%$ das respostas, demonstrando que a segurança não é a maior prioridade da empresa. Para os operários, mais de $60 \%$ acham que a segurança é a maior preocupação da empresa, representando o estágio sustentável.

- No fator comprometimento, na questão 19, o estágio reativo aparece somente na visão da equipe administrativa, mostrando que alguns gerentes acham a equipe de apoio à segurança no trabalho pequena para a empresa. Nesta questão nenhum dos respondentes considerou a empresa no estágio ideal, o sustentável, que considera a responsabilidade sobre segurança distribuída por toda a equipe.

Contudo, estas diferenças não excluem o fato de que na visão dos operários e da equipe administrativa a empresa se encontra, em sua maior parte, no estágio Sustentável, demonstrando uma visão integrada de saúde, segurança e meio ambiente.

\section{CONCLUSÕES}

A maioria das ações para atingir uma cultura de segurança ideal está mais ligada às técnicas gerenciais, corroborando a literatura no tema. Isto é possível perceber quando se comparam os resultados obtidos. Em alguns fatores os operários demonstraram uma maior importância da segurança do que o nível gerencial, provando que as práticas desenvolvidas pela empresa estão gerando bons resultados e que os próprios trabalhadores têm a consciência do seu importante papel para o sucesso da política integrada.

Um Sistema de Gestão que gerencie os riscos e busque investir na segurança do trabalho é essencial para a redução de acidentes e melhoria do ambiente, logo o conhecimento do 
estágio de maturidade da cultura de segurança que a empresa se encontra permite a adoção de medidas corretivas e/ou preventivas.

O modelo utilizado indicou que a empresa se encontra em transição entre o estágio proativo e o sustentável, nos dois níveis organizacionais. Porém, há uma concentração maior no último estágio, considerado o ideal, o estágio sustentável, comprovando sua preocupação com o bem-estar dos seus trabalhadores, o que indica o desafio da empresa em manter-se neste estágio com boas práticas quanto à segurança do trabalho. Entretanto, é importante ressaltar que o estágio patológico, o inicial, apareceu no fator informação por parte dos operários, sendo necessária uma pesquisa mais aprofundada neste tema.

Este trabalho buscou contribuir para um aprimoramento dos programas de prevenção à segurança. O método proposto pode servir de base para outras pesquisas buscando fortalecer a necessidade de uma maior preocupação e investimento em estudos voltados para o tema da cultura de segurança.

\section{REFERÊNCIAS}

AEAT - Anuário Estatístico de Acidentes do Trabalho 2017. Ministério da Fazenda, Brasília: MF, 2017, 996p.

COOPER, M. D. Towards a model of safety culture. Safety Science, n. 36, p. 111-136, 2000

GONÇALVES FILHO, A. P. Cultura e gestão de segurança no trabalho em organizações industriais: uma proposta de modelo. Tese de Doutorado em Engenharia Industrial. Universidade Federal da Bahia - Escola Politécnica. Salvador, 2011.

GONÇALVES FILHO, A. P.; ANDRADE, J. C. S.; MARINHO, M. M. O. Modelo para a gestão da cultura de segurança do trabalho em organizações industriais. Produção, vol.23, n.1, p.177-188, jan/mar. 2013.

GONÇALVES FILHO, A. P.; ANDRADE, J. C. S.; MARINHO, M. M. O. Cultura e gestão da segurança no trabalho: uma proposta de modelo. Gestão \& Produção, vol.18, n.1, p.205-220, São Carlos, 2011.

HOPKINS, A. Safety, Culture and Risk: the organizational causes of disasters. Sydney: CCH, 2005. $171 \mathrm{p}$.

HUDSON, P. T. W. Safety management and safety culture: the long, hard and winding road. Occupational health and safety management systems, p. 3-32, 2001.

PONTES, L. C. S., HONÓRIO, L. C. Cultura de Segurança do Trabalho: o caso de uma grande metalúrgica produtora de equipamentos para a construção. In: Encontro da ANPAD, 32...Anais, Rio de Janeiro, RJ, 2008.

REASON, J. Managing the risks of organizational accidents. Inglaterra: Ashgate Publishing Limited, 1997. $252 \mathrm{p}$.

WESTRUM, R. Cultures with requisite imagination. In: WISE, J. A.; HOPKIN, V. D.; STAGER, P., (Org.). Verification and Validation of Complex Systems: Human Factors Issues. New York: Springer-Verlag, 1993. p. 413-427. 